\title{
Produtividade de tomate sob adubação orgânica e complementação com adubos minerais
}

\author{
Siegfried Mueller; Anderson Fernando Wamser; Atsuo Suzuki; Walter F Becker \\ EPAGRI, EE de Caçador, C. Postal 591, 89500-000 Caçador-SC; simueller@epagri.sc.gov.br; afwamser@epagri.sc.gov.br; suzuki@ \\ epagri.sc.gov.br; wbecker@epagri.sc.gov.br
}

\section{RESUMO}

Foi avaliada a influência de doses de adubação com cama de aviário, associado ou não com adubação mineral, na produtividade do tomateiro e seus componentes. Dois experimentos foram realizados, em condições de campo, na Epagri, Estação Experimental de Caçador, durante as safras 2006/07 e 2007/08, em sistema de plantio direto. Utilizou-se o delineamento de blocos ao acaso, em esquema fatorial $4 \times 2$, sendo quatro doses de cama de aviário $\left(0,4,8\right.$ e $12 \mathrm{t} \mathrm{ha}^{-1}$, safra 2006/07; e 0, 6, 12 e 18 t ha $^{-1}$, safra 2007/08), e a complementação ou não com adubação mineral. Nos tratamentos em que houve complementação com adubação mineral, esta foi realizada até se alcançar o nível, previamente definido, recomendado para cada área. Avaliou-se a produtividade total, comercial, extra AA e extra A; a massa média de frutos comerciais, extra AA e extra A; e os teores de nutrientes na folha diagnose. A aplicação somente de adubo orgânico não foi suficiente para se conseguir as maiores produtividades comerciais, porém estas foram obtidas com a aplicação somente da adubação química ou com todas as doses de adubo orgânico complementados com adubação química $\left(100,1 \mathrm{t} \mathrm{ha}^{-1}\right)$, na safra $2007 / 08$. A produtividade comercial máxima estimada, na safra 2007/08, para somente adubo orgânico foi alcançada na dose de $16,2 \mathrm{t} \mathrm{ha}^{-1}$, produzindo 86,9 t ha $\mathrm{a}^{-1}$ de frutos de tomate.

Palavras-chave: Solanum lycopersicum, cama de aviário, nutrição de plantas.

\begin{abstract}
Tomato yield under organic fertilization and supplementation with mineral fertilizers

The influence of fertilization with poultry litter associated or not with mineral fertilization was studied on tomato yield and its components. Two experiments were carried out under field conditions in Epagri - Experimental Station of Caçador, Santa Catarina state, Brazil, during the 2006/07 and 2007/08 seasons in no-tillage system of randomized blocks design, in factorial $4 \times 2$, with four rates of poultry litter $\left(0,4,8\right.$ and $12 \mathrm{tha}^{-1}$, at season $2006 / 07$, and $0,6,12$ and $18 \mathrm{t} \mathrm{ha}^{-1}$, at season 2007/08), and the complementation or not of mineral fertilization. The mineral fertilization treatments were done in order to achieve the recommended amounts for each area. The total, marketable, extra AA and extra A fruits yield, the average mass of marketable, extra AA and extra A fruits, and the nutrient content in the leaf diagnoses were evaluated. The application of the organic manure alone was not sufficient to obtain the highest yield of fruits. The amount of organic fertilizer to achieve maximum marketable fruit yield $\left(86.9 \mathrm{t} \mathrm{ha}^{-1}\right)$ was estimated to $16.2 \mathrm{t} \mathrm{ha}^{-1}$. The higher marketable yields $\left(100.1 \mathrm{t} \mathrm{ha}^{-1}\right)$ were obtained with the application of mineral fertilizer only or with all doses of organic manure supplemented with mineral fertilizer.
\end{abstract}

Keywords: Solanum lycopersicum, poultry litter, plant nutrition.

(Recebido para publicação em 13 de abril de 2012; aceito em 28 de janeiro de 2013) (Received on April 13, 2012; accepted on January 28, 2013)

$\mathrm{O}$ estado de Santa Catarina é um dos principais produtores de carne de frango do Brasil, e neste se destacam as regiões do Meio Oeste até o Extremo Oeste. Nestas regiões, a avicultura ocorre em sistema de completo confinamento das aves, o que gera uma produção significativa de resíduos orgânicos.

O uso de material orgânico proporciona melhora na fertilidade, além de ser excelente condicionador de solo, melhorando suas características físicas, químicas e biológicas, ou seja, aumenta a retenção de água, a agregação e a porosidade do solo, aumentando assim a capacidade de troca de cátions, a fertilidade e a vida microbiana do solo, que, por sua vez, potencializam a produtividade das culturas (Terron, 1992).

Vários materiais orgânicos podem ser usados como fertilizante, sendo que as principais fontes disponíveis no meio rural são os estercos de animais, os resíduos de culturas e os adubos verdes (Sociedade..., 2004). Dentre os estercos de animais, destaca-se, na região Oeste Catarinense, a disponibilidade de cama de aviário. Estes resíduos gerados nesta região vêm sendo utilizados associados a fontes minerais na produção de tomate, associados ou não a fontes minerais na produção de milho e de outras culturas, por agricultores desta região, mas sem levar em conta suas características químicas.

Leite et al. (2003) constataram que a aplicação de composto orgânico ao solo constitui uma efetiva forma de reciclagem de nutrientes e retorno de carbono ao solo. Os mesmos autores relatam que o uso de esterco de animais combinado com adubação mineral tem sido uma estratégia importante para melhoria da fertilidade do solo.

A adição de materiais orgânicos é fundamental à qualidade do solo, em decorrência da liberação gradativa de nutrientes, que reduz processos como lixiviação, fixação e volatilização, embora esse material dependa essencialmente da sua taxa de decomposição, controlada pela temperatura, umidade, textura e mineralogia do solo, além da composição química do material orgânico utilizado (Terron, 1992).

Vários pesquisadores estudaram o efeito da incorporação de material orgânico, associado ou não à adubação mineral, sobre a cultura de tomate. Pribetic et al. (2000) verificaram, na Croácia, 
que a maior massa média de frutos foi alcançada a partir de plantas supridas com composto orgânico associado a fertilizantes minerais. Samawat et al. (2001), estudando o efeito de três níveis de adubação química e cinco níveis de vermicomposto na cultura do tomate, no Irã, sobre o crescimento das raízes e da parte aérea das plantas, massa e número de frutos, em casa de vegetação, observaram que o efeito do vermicomposto foi maior no crescimento da raiz do que no crescimento da parte aérea. Neste estudo, o vermicomposto combinado com o maior nível de adubação química proporcionou os maiores crescimentos de raízes e as maiores massas da parte aérea das plantas de tomate.

Ferreira et al. (2006), estudando a qualidade de frutos de tomate em função de doses de nitrogênio e de adubação orgânica, no caso esterco bovino curtido, verificaram que o $\mathrm{pH}$, os sólidos solúveis totais e a acidez total titulável no fruto de tomate não se alteraram com o aumento nas doses de $\mathrm{N}$, tanto na ausência como na presença da adubação orgânica. A adição de material orgânico ao solo incrementou a dose do adubo nitrogenado necessária à obtenção das máximas produções total, comercial e extra de frutos de tomate, em duas épocas de plantio (Ferreira et al., 2003).

Sabe-se que a disponibilidade de $\mathrm{N}$ para as plantas depende da taxa de mineralização do material orgânico, que vai depender da quantidade de $\mathrm{N}$ imobilizado nele disponível; da temperatura, da umidade, do $\mathrm{pH}$ e da aeração do solo; das perdas do $\mathrm{N}$ por lixiviação e da relação carbono: nitrogênio do material. Foi constatado que valores mais altos de produtividade de tomate são obtidos quando se adiciona $\mathrm{N}$ mineral ao material orgânico (Salek et al., 1981; Francis \& Cooper, 1998).

Este trabalho foi realizado com o objetivo de avaliar a influência de doses de adubação com cama de aviário, associadas ou não com adubação mineral, sobre a produtividade do tomateiro e seus componentes.

\section{MATERIAL E MÉTODOS}

Os experimentos foram realizados em condições de campo durante as safras 2006/07 e 2007/08, na Epagri, EE de Caçador, em Caçador-SC, na região fisiográfica do Alto Vale do Rio do Peixe $\left(26^{\circ} 46^{\prime} 32^{\prime \prime} \mathrm{S}, 51^{\circ} 00^{\prime} 50^{\prime \prime} \mathrm{O}\right.$, altitude média $950 \mathrm{~m}$ ). O clima é do tipo $\mathrm{Cfb}$, ou seja, temperado, constantemente úmido (Pandolfo et al., 2002). Os solos foram classificados como Latossolos Bruno distróficos típico (Sistema..., 2006). Estes apresentaram os seguintes atributos: $\mathrm{pH}$ (água) $=5,8$ e 6,$0 ; \mathrm{P}=2,9$ e $3,3 \mathrm{mg} \mathrm{dm}^{-3} ; \mathrm{K}^{+}=108,0$ e $72,0 \mathrm{mg}$ $\mathrm{dm}^{-3} ; \mathrm{MO}=5,1$ e $3,7 \mathrm{mg} \mathrm{g}^{-1} ; \mathrm{Al}^{+3}=0,0$ e 0,0 cmolc $\mathrm{L}^{-1} ; \mathrm{Ca}^{+2}=11,9$ e 9,4 cmolc $\mathrm{L}^{-1} ; \mathrm{Mg}^{+2}=3,5$ e 3,5 cmolc $\mathrm{L}^{-1}$; $\mathrm{CTC}=$

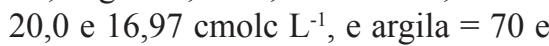
$80 \%$, para as safras 2006/07 e 2007/08, respectivamente.

Os tratamentos consistiram da combinação de quatro doses de cama de aviário $(0,4,8$ e 12 ; e $0,6,12$ e 18 t $\mathrm{ha}^{-1}$, na base seca, para as safras 2006/07 e 2007/08, respectivamente), e a complementação ou não com adubação mineral. $\mathrm{O}$ delineamento experimental foi de blocos completos ao acaso, no esquema fatorial $4 \times 2$, com quatro repetições. Cada parcela era constituída de uma fileira de 12 plantas, sendo 10 úteis, espaçadas de $1,5 \mathrm{~m}$ entre fileiras e 0,6 $\mathrm{m}$ entre plantas.

As camas de aviário apresentaram os seguintes atributos: $\mathrm{N}=25,9$ e 25,4 $\mathrm{g} \mathrm{kg}^{-1} ; \mathrm{P}=26,7$ e $16,8 \mathrm{~g} \mathrm{~kg}^{-1} ; \mathrm{K}^{+}=37,0$ e $26,4 \mathrm{~g} \mathrm{~kg}^{-1} ; \mathrm{Ca}^{+2}=68,8$ e $38,65 \mathrm{~g} \mathrm{~kg}^{-1}$; $\mathrm{Mg}^{+2}=17,0$ e $9,8 \mathrm{~g} \mathrm{~kg}^{-1} ; \mathrm{Fe}^{+2}=4.656$ e $7.075 \mathrm{mg} \mathrm{kg}^{-1}, \mathrm{Mn}^{+2}=930$ e $320 \mathrm{mg}$ $\mathrm{kg}^{-1} ; \mathrm{Zn}^{+2}=463$ e $300 \mathrm{mg} \mathrm{kg}{ }^{-1}, \mathrm{Cu}^{+2}=$ 160 e $70 \mathrm{mg} \mathrm{kg}^{-1}, \mathrm{~B}=74$ e $48 \mathrm{mg} \mathrm{kg}^{-1}$ e umidade $=43,8$ e $12,4 \%$, para as safras 2006/07 e 2007/08, respectivamente.

A partir das análises químicas das camas de aviários e dos índices de eficiência dos nutrientes no solo deste material para o primeiro ano de cultivo (para $\mathrm{N}=50 \%, \mathrm{P}=70 \%, \mathrm{~K}=100 \%$ ) (Sociedade..., 2004), foi possível calcular as quantidades de nutrientes disponíveis (QD), nas formas de $\mathrm{N}, \mathrm{P}_{2} \mathrm{O}_{5}$ e de $\mathrm{K}_{2} \mathrm{O}$. A fórmula utilizada foi $\mathrm{QD}=\mathrm{A} \times \mathrm{B} / 100$ x $\mathrm{C} / 100 \times \mathrm{D}$, em que $\mathrm{A}=$ quantidade do material orgânico aplicado, em kg ha-1 $\mathrm{B}=$ porcentagem de matéria seca do material; $\mathrm{C}=$ porcentagem do nutriente na matéria seca; $\mathrm{D}=$ índice de eficiência de cada nutriente. Os valores de nutrientes disponibilizados nas camas de aviários utilizadas, nas safras 2006/07 e 2007/08, são apresentados na Tabela 1.

A recomendação de adubação, de acordo com as análises de solo das áreas experimentais, foi 450 e $500 \mathrm{~kg} \mathrm{ha}^{-1} \mathrm{de}$ $\mathrm{N}, 600$ e $600 \mathrm{~kg} \mathrm{ha}^{-1}$ de $\mathrm{P}_{2} \mathrm{O}_{5} ; 600$ e 600 $\mathrm{kg} \mathrm{ha}^{-1}$ de $\mathrm{K}_{2} \mathrm{O}$, para as safras 2006/07 e 2007/08, respectivamente (Sociedade..., 2004). Levando-se em consideração a adubação recomendada e os nutrientes $\mathrm{N}, \mathrm{P}_{2} \mathrm{O}_{5}, \mathrm{~K}_{2} \mathrm{O}$ disponibilizados pela cama de aviário, houve necessidade de complementação com adubação mineral para todas as doses, conforme apresentado na Tabela 1.

Com relação à adubação mineral, na safra 2006/07 o N e o K foram aplicados $1 / 3$ na base e $2 / 3$ em cobertura. Todavia, na safra 2007/08, o $\mathrm{N}$ foi aplicado $1 / 10$ na base e 9/10 em cobertura, e o K 1/5 na base e 4/5 em cobertura. As fontes de adubos utilizados na adubação foram nitrato de amônio, superfosfato triplo e cloreto de potássio A adubação com cama de aviário foi toda aplicada no sulco de plantio duas semanas antes do transplante das mudas. As adubações de cobertura, com adubo mineral nitrogenado (nitrato de amônio) e potássico (cloreto de potássio), foram realizadas semanalmente a partir dos 21 dias após o plantio (DAP) conforme os tratamentos implantados, que também receberam, nas duas safras, 3,3 $\mathrm{kg} \mathrm{ha}^{-1}$ de $\mathrm{B}$, na forma de bórax, por ocasião da adubação de plantio.

Utilizou-se na safra 2006/07 a cv. 'Styllus' da Horticeres, e na safra 2007/08, a 'Alambra' da Clause/Tesier. O sistema de plantio foi direto na palha de aveia preta, sem aplicação de herbicida. As mudas foram transplantadas em 10 e 19 de novembro de 2006 e 2007 , respectivamente, e cada planta foi conduzida com duas hastes, no método de tutoramento vertical com fitilhos. As demais práticas culturais foram realizadas de acordo com as indicações técnicas para o tomateiro tutorado na região do Alto Vale do Rio do Peixe (Mueller et al., 2008).

Para a análise química das folhas de tomateiro, as amostras foram constituídas a partir da coleta da terceira folha (com pecíolo) a partir do ápice, das plantas úteis da parcela, por ocasião do $1^{\circ}$ fruto maduro. As amostras 
foliares foram secas em estufa com circulação forçada de ar a uma temperatura de $70-75^{\circ} \mathrm{C}$ até peso constante. Após a secagem, foi feita a moagem do material foliar em moinho Willey com peneira de 20 "mesh". As amostras foram digeridas por via úmida, empregando-se a digestão nitro-perclórica (Sarruge \& Haag, 1974). Os teores de $P$ foram determinados colorimetricamente pelo método de vanado-molibdato de amônia, e os teores de $\mathrm{K}, \mathrm{Ca}, \mathrm{Mg}, \mathrm{Fe}, \mathrm{Mn}, \mathrm{Zn}$ e $\mathrm{Cu}$ por espectrofotometria de absorção atômica. Os teores de $\mathrm{N}$ foram determinados por Semi-Micro-Kjeldahl (Sarruge \& Haag, 1974). A determinação dos teores de B foi feita através da mineralização por via seca, com calcinação em mufla a $550^{\circ} \mathrm{C}$ e empregando-se o método Azometina-H em espectrofotometria (Bataglia et al., 1983). As análises dos tecidos foram realizadas em laboratório da Estação Experimental de Caçador da Epagri.

Avaliou-se a produtividade total, comercial, extra AA e extra A ( $\left.\mathrm{t} \mathrm{ha}^{-1}\right)$; a massa média de frutos comerciais, extra AA e extra A ( $\mathrm{g}_{\text {fruto }}{ }^{-1}$ ). Foram considerados frutos extra AA os com massa média maior que $150 \mathrm{~g}$ e frutos extra A com massa média entre 100 e $150 \mathrm{~g}$.

As variáveis estudadas foram submetidas à análise de variância (teste F). Havendo significância estatística $(\mathrm{p} \leq 0,05)$, as médias foram estudadas por meio da análise de regressão polinomial. As análises estatísticas foram realizadas através do pacote estatístico SISVAR versão 5.0 (Ferreira, 2008).

\section{RESULTADOS E DISCUSSÃO}

Houve interação entre os fatores doses de cama de aviário e complementação com adubação mineral para as produtividades comercial, total, extra AA e extra A, além da massa média comercial, extra AA e extra A dos frutos de tomate colhidos na safra 2006/07, enquanto na safra 2007/08 isto só não ocorreu para produtividade de frutos extra A. Já para os teores de macro e micronutrientes na folha diagnosticada, não houve interação entre os fatores estudados.

$\mathrm{Na}$ safra 2006/07, a aplicação de cama de aviário sem a complementação mineral proporcionou aumento linear

Tabela 1. Quantidade dos nutrientes nas formas de $\mathrm{N}, \mathrm{P}_{2} \mathrm{O}_{5}$ e $\mathrm{K}_{2} \mathrm{O}$ disponibilizados pelo adubo orgânico e pela complementação com adubo mineral, em função das doses de cama de aviário (amount of $\mathrm{N}, \mathrm{P}_{2} \mathrm{O}_{5}, \mathrm{~K}_{2} \mathrm{O}$ provided by organic manure and mineral fertilizer complementation, depending on the rates of poultry manure). Caçador, Epagri, 2011.

\begin{tabular}{|c|c|c|c|c|c|c|}
\hline \multirow{2}{*}{$\begin{array}{l}\text { Doses de cama } \\
\text { de aviário (t/ha) }\end{array}$} & \multicolumn{3}{|c|}{$\begin{array}{c}\text { Disponibilização pelo } \\
\text { adubo orgânico (kg/ha) }\end{array}$} & \multicolumn{3}{|c|}{$\begin{array}{l}\text { Complementação com } \\
\text { adubo mineral (kg/ha) }\end{array}$} \\
\hline & $\mathbf{N}$ & $\mathbf{P}_{2} \mathbf{O}_{5}$ & $\mathrm{~K}_{2} \mathrm{O}$ & $\mathbf{N}$ & $\mathrm{P}_{2} \mathrm{O}_{5}$ & $\mathrm{~K}_{2} \mathrm{O}$ \\
\hline & \multicolumn{6}{|c|}{ Safra 2006/07 } \\
\hline 0 & 0,0 & 0,0 & 0,0 & 450,0 & 600,0 & 600,0 \\
\hline 4 & 51,3 & 193,5 & 175,8 & 398,7 & 406,5 & 424,2 \\
\hline 8 & 102,6 & 387,0 & 351,6 & 347,4 & 213,0 & 248,4 \\
\hline \multirow[t]{2}{*}{12} & 153,9 & 580,5 & 527,4 & 296,1 & 19,5 & 72,6 \\
\hline & \multicolumn{6}{|c|}{ Safra 2007/08 } \\
\hline 0 & 0,0 & 0,0 & 0,0 & 500,0 & 600,0 & 600,0 \\
\hline 6 & 78,0 & 165,4 & 194,6 & 422,0 & 434,6 & 405,4 \\
\hline 12 & 155,9 & 330,9 & 389,2 & 344,1 & 269,1 & 210,8 \\
\hline 18 & 233,9 & 496,3 & 583,8 & 266,1 & 103,7 & 16,2 \\
\hline
\end{tabular}

${ }^{1}$ Quantidades de nutrientes determinadas a partir da quantidade de adubo orgânico aplicado conforme os tratamentos, a partir do teor de nutrientes das camas de aviário e dos índices de eficiência dos nutrientes no solo para o primeiro ano de cultivo (amount of nutrient determined from the amount of organic manure applied according to treatments, the nutrient content of poultry manure and efficiency ratios of nutrients in the soil for the first year of cultivation).

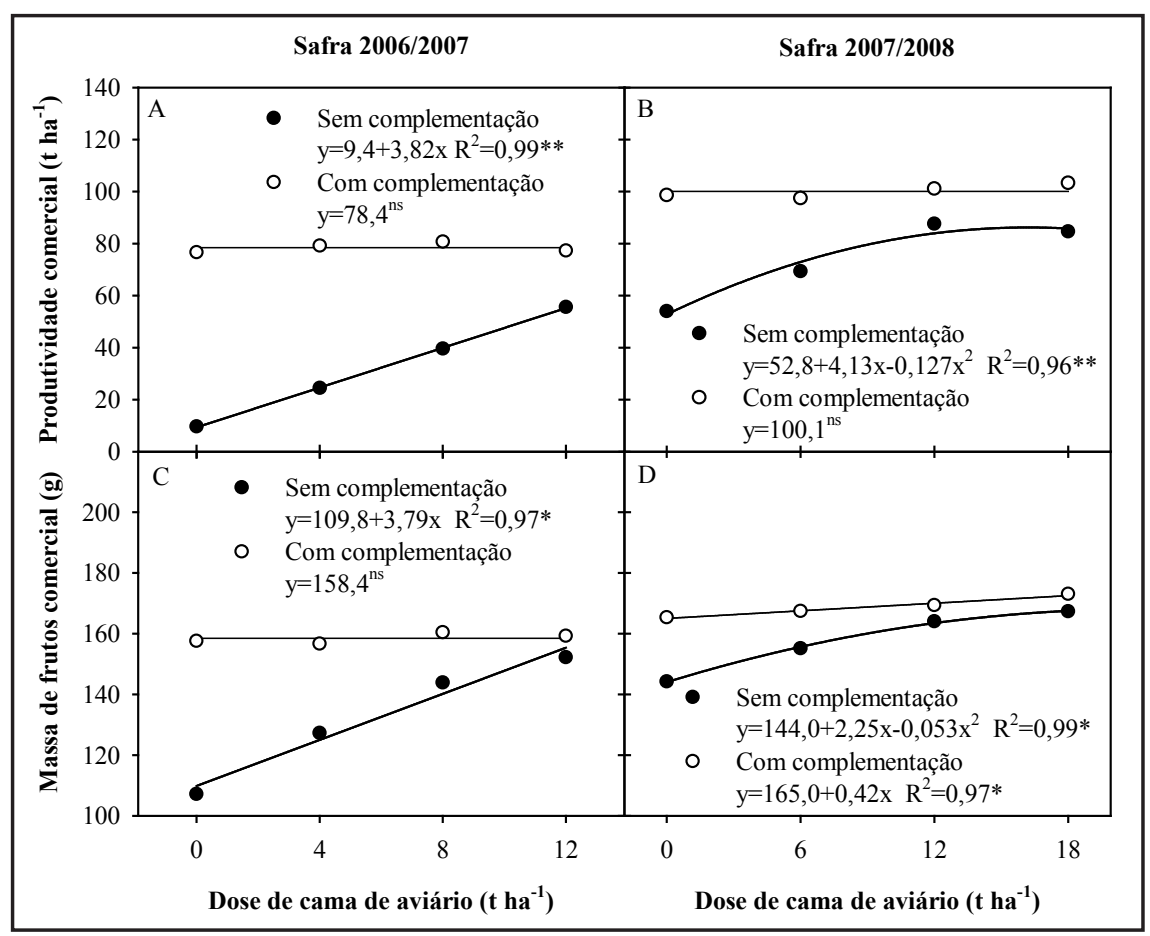

Figura 1. Produtividade e massa média de frutos comerciais de tomate em função de doses de adubo orgânico e da complementação com adubos minerais (yield and average mass of marketable tomato fruit depending on doses of poultry manure and mineral supplementation). Caçador, Epagri, 2011.

da produtividade comercial de frutos (Figura 1A). Entretanto, a produtividade obtida na maior dose foi inferior aos tratamentos que receberam adubação mineral. Este comportamento foi seme- lhante para as variáveis: produtividades total, extra AA e extra A (Tabela 2). Entretanto na safra 2007/08, a aplicação de cama de aviário sem a complementação mineral proporcionou aumento quadráti- 
Tabela 2. Produtividade total, extra AA e extra A ( $t /$ ha) de tomate em função de doses de cama de aviário e da complementação mineral (total yield, extra AA and extra A (t/ha) yield, of tomato depending on poultry manure and mineral supplementation). Caçador, Epagri, 2011.

\begin{tabular}{|c|c|c|c|c|c|c|}
\hline \multirow{3}{*}{$\begin{array}{l}\text { Doses de } \\
\text { cama de } \\
\text { aviário (t/ha) }\end{array}$} & \multicolumn{6}{|c|}{ Complementação com adubos minerais } \\
\hline & Sem & Com & Sem & Com & Sem & Com \\
\hline & \multicolumn{2}{|l|}{ Total } & \multicolumn{2}{|l|}{ Extra AA } & \multicolumn{2}{|c|}{ Extra A } \\
\hline & \multicolumn{6}{|c|}{ Safra 2006/07 } \\
\hline 0 & $14,3 \mathrm{~B}$ & $83,6 \mathrm{~A}$ & $2,4 \mathrm{~B}$ & $43,8 \mathrm{~A}$ & $7,3 \mathrm{~B}$ & $32,8 \mathrm{~A}$ \\
\hline 4 & $34,0 \mathrm{~B}$ & $87,6 \mathrm{~A}$ & $8,2 \mathrm{~B}$ & $44,1 \mathrm{~A}$ & $16,2 \mathrm{~B}$ & $35,1 \mathrm{~A}$ \\
\hline 8 & $49,7 \mathrm{~B}$ & 90,9 A & 19,4 B & $46,5 \mathrm{~A}$ & $20,2 \mathrm{~B}$ & $34,3 \mathrm{~A}$ \\
\hline 12 & $66,7 \mathrm{~B}$ & $86,6 \mathrm{~A}$ & $30,5 \mathrm{~B}$ & $42,8 \mathrm{~A}$ & $25,1 \mathrm{~B}$ & $34,4 \mathrm{~A}$ \\
\hline Regressão & $\hat{y}=15,3+4,32 x$ & $\mathrm{Y}=80,0^{\mathrm{ns}}$ & $\hat{y}=0,8+2,39 x$ & $\mathrm{Y}=80,0^{\mathrm{ns}}$ & $\hat{y}=8,6+1,43 x$ & $\mathrm{Y}=80,0^{\text {ns }}$ \\
\hline \multirow[t]{2}{*}{$\mathrm{R}^{2}$} & $0,99^{* *}$ & - & $0,98^{* *}$ & - & $0,97^{*}$ & - \\
\hline & \multicolumn{6}{|c|}{ Safra 2007/08 } \\
\hline 0 & $60,7 \mathrm{~B}$ & $105,5 \mathrm{~A}$ & $21,8 \mathrm{~B}$ & $63,4 \mathrm{~A}$ & $32,2 \mathrm{~A}$ & $35,2 \mathrm{~A}$ \\
\hline 6 & $76,3 \mathrm{~B}$ & $104,1 \mathrm{~A}$ & $36,8 \mathrm{~B}$ & $62,9 \mathrm{~A}$ & $32,5 \mathrm{~A}$ & $34,5 \mathrm{~A}$ \\
\hline 12 & $96,0 \mathrm{~B}$ & $107,5 \mathrm{~A}$ & $54,0 \mathrm{~B}$ & $67,5 \mathrm{~A}$ & $33,6 \mathrm{~A}$ & $33,6 \mathrm{~A}$ \\
\hline 18 & $91,7 \mathrm{~B}$ & $110,8 \mathrm{~A}$ & $55,0 \mathrm{~B}$ & $69,9 \mathrm{~A}$ & $29,6 \mathrm{~A}$ & $33,4 \mathrm{~A}$ \\
\hline Regressão & $\hat{\mathrm{y}}=59,3+4,37 \mathrm{x}-0,138 \mathrm{x}^{2}$ & $\mathrm{Y}=107,0^{\mathrm{ns}}$ & $\hat{\mathrm{y}}=20,8+3,70 \mathrm{x}-0,097 \mathrm{x}^{2}$ & $\mathrm{Y}=65,9^{\mathrm{ns}}$ & $\mathrm{Y}=32,0^{\mathrm{ns}}$ & $\mathrm{Y}=34,2^{\text {ns }}$ \\
\hline $\mathrm{R}^{2}$ & $0,95^{* *}$ & - & $0,98^{* *}$ & - & - & - \\
\hline
\end{tabular}

${ }^{* *}$ Médias seguidas pelas mesmas letras na linha não se diferem pelo teste $\mathrm{F}$ a $5 \%$ de significância (means followed by same letters in the line do not differ by $\mathrm{F}$ test at 5\% significance); ${ }^{*}$ Regressões polinomiais significativas a 1 e $5 \%$ de significância, respectivamente (polynomial regressions significant at 1 and 5\% significance, respectively); ns não houve diferenças entre os níveis do fator doses de adubo orgânico a $5 \%$ de significância (there were no differences between the levels of organic manure at 5\% significance).

co da produtividade comercial de frutos, alcançando a máxima produtividade na dose estimada de 16,3 $\mathrm{t} \mathrm{ha}^{-1}$ (Figura 1B). Mesmo utilizando maiores doses de cama de aviário na safra 2007/08, em relação à safra anterior, novamente a maior produtividade comercial obtida com a aplicação somente de cama de aviário foi inferior aos tratamentos que receberam adubação mineral. Para a produtividade total e extra AA, o comportamento foi semelhante alcançando as máximas produtividades nas doses estimadas de 15,8 e 19,1 $\mathrm{t} \mathrm{ha}^{-1}$, respectivamente (Tabela 2).

As menores produtividades com a adubação orgânica, em relação à complementação com adubação mineral, podem ser atribuídas, num primeiro momento, ao não suprimento das quantidades de N, P e K recomendadas para a cultura, mesmo na maior dose utilizada (Tabela 1). Entretanto, fica evidente na segunda safra, na qual foram utilizadas doses maiores de cama de aviário, que os suprimentos das quantidades de $\mathrm{N}$, $\mathrm{P}$ e K com a adubação orgânica deixam de ser limitantes, visto que há a estabilização das produtividades de frutos a partir da dose de 16,3 $\mathrm{t} \mathrm{ha}^{-1}$. Alguns aspectos podem estar limitando as respostas da cultura à adubação orgânica. O primeiro diz respeito ao desiquilíbrio existente nas quantidades dos macronutrientes primários $\mathrm{N}, \mathrm{P}$ e $\mathrm{K}$ da cama de aviário, visto que estes nutrientes não estão na mesma proporção das exigidas pela cultura do tomate conforme as recomendações da Sociedade... (2004). Por outro lado, pode existir uma falta de sincronismo entra a mineralização dos nutrientes do adubo orgânico e as épocas de maior acúmulo de nutrientes pela cultura. De acordo com Fayad et al. (2002), a época de maior absorção de nutrientes coincide com o início da frutificação, correspondendo para o $\mathrm{N}$ aos 46 dias após o plantio. Entretanto, Azeez \& Van Averbeke (2010), avaliando a taxa de mineralização de $\mathrm{N}$ de estercos de origem animal, observaram que o $\mathrm{N}$ é mineralizado rapidamente nos primeiros 30 dias de aplicação, podendo implicar perdas de $\mathrm{N}$ por lixiviação se o período de maior absorção de $\mathrm{N}$ pelas culturas não coincidir com esta época.

As maiores produtividades comerciais foram obtidas para todas as doses de adubo orgânico em associação à adubação mineral, não diferindo da adubação exclusiva com adubo mineral, em ambas as safras. Assim, estes resultados mostram que o adubo orgânico, quando associado à complementação com adubação mineral, supre a demanda da cultura pelos macronutrientes primários. Estas respostas se assemelham às obtidas por Lu et al. (2011), ao avaliarem o balanceamento de N, P e K com adubos orgânicos e minerais. Quando este não é feito, muitas vezes a adição de adubos minerais ao adubo orgânico promove menores produtividades em relação à adubação orgânica ou química isolada (Taiwo et al., 2007). Por outro lado, a associação de adubos minerais à cama de aviário, principalmente nitrogenados, pode auxiliar na decomposição do material orgânico, aumentando a velocidade de liberação dos nutrientes para a solução do solo. Isto é importante para adubos de cama de aviário, pois na sua composição, além de esterco, existe uma porção de farelo de madeira, que possui uma alta relação $\mathrm{C} / \mathrm{N}$, imobilizando temporariamente o N. Por fim, é preciso considerar também que a adubação 
Tabela 3. Massa média de frutos ( $\mathrm{g}$ ) de tomate em função de doses de cama de aviário e da complementação mineral (fruit average mass depending on doses of poultry manure and mineral supplementation). Caçador, Epagri, 2011.

\begin{tabular}{|c|c|c|c|c|}
\hline \multirow{3}{*}{$\begin{array}{l}\text { Doses de cama de } \\
\text { aviário (t/ha) }\end{array}$} & \multicolumn{2}{|c|}{ Extra AA } & \multicolumn{2}{|c|}{ Extra A } \\
\hline & \multicolumn{2}{|c|}{ Complementação com adubos minerais } & \multicolumn{2}{|c|}{ Complementação com adubos minerais } \\
\hline & Sem & Com & Sem & Com \\
\hline & \multicolumn{4}{|c|}{ Safra 2006/07 } \\
\hline 0 & $133,4 \mathrm{~B}$ & $188,1 \mathrm{~A}$ & $103,0 \mathrm{~B}$ & $129,4 \mathrm{~A}$ \\
\hline 4 & $153,8 \mathrm{~B}$ & $193,6 \mathrm{~A}$ & $118,2 \mathrm{~B}$ & $126,6 \mathrm{~A}$ \\
\hline 8 & $172,2 \mathrm{~B}$ & $185,3 \mathrm{~A}$ & $126,4 \mathrm{~B}$ & $135,6 \mathrm{~A}$ \\
\hline 12 & $186,9 \mathrm{~A}$ & $189,5 \mathrm{~A}$ & $124,4 \mathrm{~B}$ & $133,4 \mathrm{~A}$ \\
\hline Regressão & $\hat{y}=134,8+4,47 x$ & $\mathrm{Y}=189,1^{\mathrm{ns}}$ & $\hat{y}=102,9+5,04 x-0,269 x^{2}$ & $\mathrm{Y}=131,2^{\mathrm{ns}}$ \\
\hline \multirow[t]{2}{*}{$\mathrm{R}^{2}$} & $0,99^{* *}$ & - & $0,99^{*}$ & - \\
\hline & \multicolumn{4}{|c|}{ Safra 2007/08 } \\
\hline 0 & $176,8 \mathrm{~B}$ & $189,7 \mathrm{~A}$ & $128,1 \mathrm{~B}$ & $134,5 \mathrm{~A}$ \\
\hline 6 & $185,7 \mathrm{~B}$ & $192,5 \mathrm{~A}$ & $130,8 \mathrm{~B}$ & $135,3 \mathrm{~A}$ \\
\hline 12 & $191,3 \mathrm{~A}$ & 193,4 A & $133,7 \mathrm{~A}$ & $135,4 \mathrm{~A}$ \\
\hline 18 & $195,2 \mathrm{~A}$ & $198,4 \mathrm{~A}$ & $132,5 \mathrm{~B}$ & $136,6 \mathrm{~A}$ \\
\hline Regressão & $\hat{y}=178,1+1,01 x$ & $\hat{y}=189,4+0,45 x$ & $\hat{y}=127,9+0,64 x-0,020 x^{2}$ & $\mathrm{Y}=135,4^{\mathrm{ns}}$ \\
\hline $\mathrm{R}^{2}$ & $0,97^{*}$ & $0,92^{*}$ & $0,95^{*}$ & - \\
\hline
\end{tabular}

${ }^{* *}$ Médias seguidas pelas mesmas letras na linha não se diferem pelo teste $\mathrm{F}$ a $5 \%$ de significância (means followed by same letters in the line do not differ by $\mathrm{F}$ test at 5\% significance); ${ }^{*}$ Regressões polinomiais significativas a 1 e $5 \%$ de significância, respectivamente (polynomial regressions significant at 1 and 5\% significance, respectively); ns não houve diferenças entre os níveis do fator doses de adubo orgânico a $5 \%$ de significância (there were no differences between the levels of organic manure at $5 \%$ significance).

Tabela 4. Teores de macro e micronutrientes da folha diagnose do tomateiro em função de doses de adubo orgânico e da complementação com adubos minerais (levels of macro and micronutrients diagnosis of tomato leaf depending on doses of organic manure and chemical fertilizers to complement). Caçador, Epagri, 2011.

\begin{tabular}{|c|c|c|c|c|c|c|c|c|c|c|}
\hline \multirow{2}{*}{$\begin{array}{l}\text { Doses de cama } \\
\text { de aviário (t/ha) }\end{array}$} & \multicolumn{5}{|c|}{ Macronutrientes (g/kg) } & \multicolumn{5}{|c|}{ Micronutrientes (mg/kg) } \\
\hline & $\mathbf{N}$ & $\mathbf{P}$ & $\mathbf{K}$ & $\mathbf{C a}$ & $\mathrm{Mg}$ & $\mathrm{Fe}$ & $\mathbf{Z n}$ & Mn & $\mathrm{Cu}$ & B \\
\hline & \multicolumn{10}{|c|}{ Safra 2006/2007 } \\
\hline 0 & $32,5^{\text {ns }}$ & $2,5^{\mathrm{ns}}$ & $23,7^{\text {ns }}$ & $25,0^{\mathrm{ns}}$ & $5,7^{\mathrm{ns}}$ & $132^{\mathrm{ns}}$ & $24^{\mathrm{ns}}$ & $176^{1}$ & $2417^{2}$ & $26^{3}$ \\
\hline 4 & 31,7 & 2,9 & 23,3 & 23,3 & 5,8 & 135 & 27 & 159 & 2334 & 28 \\
\hline 8 & 31,9 & 2,8 & 25,2 & 23,7 & 5,8 & 140 & 22 & 123 & 2217 & 27 \\
\hline 12 & 30,6 & 2,8 & 26,2 & 22,9 & 5,8 & 130 & 22 & 128 & 2024 & 32 \\
\hline Sem & $26,8^{*}$ & $2,6^{*}$ & $22,0^{*}$ & $23,1^{\mathrm{ns}}$ & $5,8^{\mathrm{ns}}$ & $125^{*}$ & $26^{*}$ & $154^{\mathrm{ns}}$ & $308^{\mathrm{ns}}$ & $29^{\mathrm{ns}}$ \\
\hline \multirow[t]{2}{*}{ Com } & 36,6 & 2,9 & 27,1 & 24,4 & 5,8 & 144 & 22 & 139 & 229 & 27 \\
\hline & \multicolumn{10}{|c|}{ Safra 2007/2008 } \\
\hline 0 & $39,8^{\text {ns }}$ & $2,4^{\mathrm{ns}}$ & $22,5^{\text {ns }}$ & $38,1^{\text {ns }}$ & $5,8^{\text {ns }}$ & $187^{\mathrm{ns}}$ & $153^{\text {ns }}$ & $126^{\mathrm{ns}}$ & $893^{4}$ & $52^{5}$ \\
\hline 6 & 40,2 & 2,7 & 21,3 & 37,8 & 5,7 & 206 & 159 & 120 & 913 & 54 \\
\hline 12 & 39,8 & 2,6 & 21,0 & 38,8 & 5,7 & 189 & 160 & 119 & 814 & 58 \\
\hline 18 & 37,8 & 2,6 & 19,6 & 35,9 & 5,6 & 226 & 133 & 109 & 717 & 50 \\
\hline Sem & $38,3^{*}$ & $2,6^{\mathrm{ns}}$ & $20,2^{*}$ & $38,5^{\text {ns }}$ & $6,0^{*}$ & $207^{\mathrm{ns}}$ & $154^{\mathrm{ns}}$ & $119^{\mathrm{ns}}$ & $857^{\text {ns }}$ & $54^{\mathrm{ns}}$ \\
\hline Com & 40,6 & 2,6 & 22,1 & 36,8 & 5,4 & 197 & 148 & 119 & 811 & 53 \\
\hline
\end{tabular}

${ }^{\text {ns Não houve diferenças entre os níveis dos fatores analisados (there were no differences between the levels of the factors analyzed); }{ }^{*} \text { Houve }}$ diferença significativa entre os níveis do fator complementação com adubação mineral pelo teste $\mathrm{F}$ a 5\% de significância (there were significant difference between levels of factor supplementation with mineral fertilizer by $\mathrm{F}$ test at $5 \%$ significance); ${ }^{1} \hat{\mathrm{y}}=173,5-4,50 \mathrm{x}\left(\mathrm{R}^{2}=0,84^{*}\right) ;{ }^{2} \hat{\mathrm{y}}=$ $2.442,4-32,40 \mathrm{x}\left(\mathrm{R}^{2}=0,96^{* *}\right) ;{ }^{3} \hat{\mathrm{y}}=25,7+0,425 \mathrm{x}\left(\mathrm{R}^{2}=0,70^{*}\right) ;{ }^{4} \hat{\mathrm{y}}=928,3-10,45 \mathrm{x}\left(\mathrm{R}^{2}=0,82^{*}\right) ;{ }^{5} \hat{\mathrm{y}}=51,3+1,217 \mathrm{x}-0,069 \mathrm{x}^{2}\left(\mathrm{R}^{2}=0,72^{*}\right)$. 
mineral foi feita de forma parcelada semanalmente, a partir dos 21 dias após o plantio, o que faz com que haja uma maior disponibilidade de nutrientes na fase de maior crescimento e acúmulo de nutrientes pelas plantas.

A massa média de fruto comercial aumentou linearmente com o incremento nas doses de cama de aviário, na safra 2006/07, e de forma quadrática, na safra 2007/08, alcançando o maior valor com a dose estimada de 21,2 $\mathrm{t} \mathrm{ha}^{-1}$ (Figura 1). Para as duas safras, a massa média de frutos extra AA aumentou de forma linear ao aumento das doses de adubo orgânico, enquanto que a massa média de frutos extra A aumentou de forma quadrática (Tabela 3). Estes resultados permitem inferir que a adubação orgânica promove o aumento da massa média de frutos comerciais de maior classificação, visto que os frutos de classe extra AA, de maior calibre, continuaram crescendo de forma linear, enquanto os frutos extra A, de menor calibre, alcançam suas maiores massas nas doses estimadas de 9,4 e 16,0 $\mathrm{t} \mathrm{ha}^{-1}$, para as safras 2006/07 e 2007/08, respectivamente. O efeito do adubo orgânico sobre a massa de frutos fica evidente na safra 2007/08, na qual a massa de frutos comerciais aumentou linearmente quando houve adubação orgânica complementada com adubo mineral, em relação somente à adubação mineral. Um dos aspectos positivos da adubação orgânica é que ela fornece não somente macronutrientes primários, mas também macronutrientes secundários, como o Ca e o $\mathrm{Mg}$, e micronutrientes, e isto pode ter contribuído com o aumento da massa média de frutos extra AA e comercial quando se aumentaram as doses de adubo orgânico complementado com adubo mineral na safra 2007/2008.

Os teores de macronutrientes na folha diagnosticada não foram afetados pelas doses de adubo orgânico em ambas as safras (Tabela 4). Entretanto, para N, P e K, na safra 2006/07, e N e K, na safra 2007/08, os teores foliares foram maiores quando houve complementação com adubação mineral. Assim, as maiores produtividades obtidas com aplicação somente de adubo mineral ou as aplicações associadas de adubo orgânico e mineral estão também relacionadas aos maiores teores foliares de macronutrientes primários.

Com relação aos micronutrientes, as respostas foram variáveis conforme a safra, com exceção do $\mathrm{Cu}$ e do B, que em ambas as safras foram afetadas pelas doses de adubo orgânico. O teor foliar de $\mathrm{Cu}$ diminuiu linearmente com o aumento das doses de cama de aviário. Esta diminuição pode estar relacionada à complexação do cobre do solo pelo material orgânico fornecido e assim, há menor disponibilidade à planta de tomate. Hodgson (1963) relata que os ácidos húmico e fúlvico, presentes na matéria orgânica, têm papel importante na adsorção do cobre. Já o boro apresentou um incremento linear na safra 2006/07 e quadrático na safra 2007/008. Este aumento do teor foliar de boro do tomateiro, provavelmente, se deve à adição de material orgânico pois, conforme Scaramuzza et al. (2002), a matéria orgânica é a principal fonte de B no solo.

Conclui-se que as maiores produtividades comerciais de tomate são obtidas com a aplicação somente da adubação mineral ou com a aplicação de adubo orgânico complementado com adubo mineral ou seja $\left(100,1 \mathrm{t} \mathrm{ha}^{-1}\right)$, na safra 2007/08; a adubação orgânica com cama de aviário, sem a suplementação da adubação mineral, não permite obter produtividades comerciais de tomate semelhantes à adubação mineral, alcançando somente a produtividade máxima estimada de 86,9 $\mathrm{t} \mathrm{ha}^{-1}$ de frutos de tomate, na safra 2007/08, na dose de 16,2 t ha $^{-1}$ de adubo orgânico de frangos.

\section{AGRADECIMENTOS}

Ao técnico agrícola Luciano Caetano, funcionário da Epagri, EE de Caçador, pela colaboração na realização do experimento. Ao pesquisador aposentado da Epagri Clori Basso, pelas valiosas sugestões durante o planejamento e a realização dos experimentos.

\section{REFERÊNCIAS}

AZEEZ JO; AVERBEKE WV. 2010. Nitrogen mineralization potential of three animal manures applied on a sandy clay loam soil. Bioresource Technology 101: 5645-5651.

BATAGLIA OC; FURLANI AMC; TEIXEIRA JPF; FURLANI PR; GALLO JR. 1983
Métodos de análise química de plantas. Campinas, Instituto Agronômico. 48p. (Boletim Técnico, 78).

FAYAD JA; FONTES PCR; CARDOSO AA; FINGER FL; FERREIRA FA. 2002. Absorção de nutrientes pelo tomateiro cultivado sob condições de campo e de ambiente protegido. Horticultura brasileira 20: 90-94.

FERREIRA DF. 2008. SISVAR: um programa para análises e ensino de estatística. Revista Symposium 6: 36-41.

FERREIRA MMM; FERREIRA GB; FONTES PCR. 2003. Produção do tomateiro em função de doses de nitrogênio e da adubação orgânica em duas épocas de cultivo. Horticultura Brasileira 21: 468-473.

FERREIRA MMM; FERREIRA GB; FONTES PCR; DANTAS JP. 2006. Qualidade do tomate em função de doses de nitrogênio e da adubação orgânica em duas estações. Horticultura Brasileira 24: 141-145.

FRANCIS PB; COOPER PE. 1998. Rate and timing of nitrogen fertilization on yield and gross revenue of fresh market tomatoes following a winter legume cover crop. Journal of Vegetable Crop Production 4: 55-65.

HODGSON JF. Chemistry of the micronutrient elements in soils. 1963. Advances in Agronomy 15: 119-59.

LEITE LFC; MENDONÇA ES; NEVES JCL; MACHADO PLO; GALVÃO JCC. 2003. Estoques totais de carbono orgânico e seus compartimentos em argissolo sob floresta e sob milho cultivado com adubação mineral e orgânica. Revista Brasileira de Ciência do Solo 27: 821-832.

LU HJ; YE ZQ; ZHANG XL; LIN XY; NI WZ. 2011. Growth and yield responses of crops and macronutrient balance influenced by commercial organic manure used as a partial substitute for chemical fertilizers in an intensive vegetable cropping system. Physics and Chemistry of the Earth 36: 387-394.

MUELLER S; WAMSER AF; BECKER WF; SANTOS JP. 2008. Indicações técnicas para o tomateiro tutorado na Região do Alto Vale do Rio do Peixe. Florianópolis: Epagri. 78p. (Epagri. Sistemas de Produção...).

PANDOLFO C; BRAGA HJ; SILVA JÚNIOR VP. 2002. Atlas climatológico digital do Estado de Santa Catarina. Florianópolis: Epagri (CD-ROM).

PRIBETIC D; JURISIC M; VLAKETIC I. 2000. Tomato yield depending on fertilization. Agronomski Glasnik 62: 345-356.

SALEK RC; ALMEIDA DL; OLIVEIRA MF; PENTEADO AF. 1981. Efeito do esterco de galinha e sua associação com fertilizantes sobre a produção do tomateiro no município de Teresópolis-RJ. Niterói: PESAGRO-Rio 3p. (Comunicado Técnico, 70).

SAMAWAT S; LAKZIAN A; ZAMIRPOUR A. 2001. The effect of vermicompost on growth characteristics of tomato. Agricultural Sciences and Technology 15: 83-89.

SARRUGE JR; HAAG HP. 1974. Análises químicas em plantas. Piracicaba: ESALQ, 56p.

SCARAMUZZA JF; COUTO EG; SELVA EC; TONON L. 2002. Estudo da distribuição 
espacial entre boro e matéria orgânica $e$ entre fósforo e zinco, em um solo de Nova Mutum-MT. In: Simpósio Internacional de Agricultura de Precisão, 2. USP/ESALQ. Viçosa (CD-ROM).

SISTEMA BRASILEIRO DE CLASSIFICAÇÃO DE SOLOS. 2006. 2. ed. Rio de Janeiro:
Embrapa Solos, 306 p. Inclui apêndices. SOCIEDADE BRASILEIRA DE CIÊNCIA DO SOLO. 2004. Manual de Adubação e Calagem para os Estados do Rio Grande do Sul e Santa Catarina. 10 ed. Porto Alegre: Núcleo regional Sul; Comissão de Química e Fertilidade do Solo RS/SC. 394p.
TAIWO LB; ADEDIRAN JA; SONUBI OA. 2007. Yield and Quality of Tomato Grown with Organic and Synthetic Fertilizers. International Journal of Vegetable Science 13: 5-19.

TERRON PU. 1992. Tratado de fitotecnia general. 2ed. Madrid. 895p. 